\title{
INCIDÊNCIA E ÍNDICE DE DOENÇA DO MOSAICO DO TRIGO EM CEREAIS DE INVERNO E EM GRAMÍNEAS DE VERÃO, ASSOCIADOS AO Polymyxa graminis*
}

\author{
MARISA DALBOSCO ${ }^{1}$, JUREMA SCHONS ${ }^{1} \&$ ARIANO M. PRESTES ${ }^{2}$
}

\author{
${ }^{1}$ Faculdade de Agronomia e Medicina Veterinária, Universidade de Passo Fundo, Cx. Postal 611, CEP 99001-970, Passo \\ Fundo, RS, e-mail: schons@upf.tche.br; ${ }^{2}$ Embrapa Trigo, Cx. Postal 569, CEP 99001-970, Passo Fundo, RS
}

(Aceito para publicação em 30/08/2001)

Autor para correspondência: Jurema Schons

DALBOSCO, M., SCHONS, J. \& PRESTES, A.M. Incidência e índice de doença do mosaico do trigo em cereais de inverno e em gramíneas de verão, associados ao Polymyxa graminis. Fitopatologia Brasileira 27:048-052. 2002.

\section{RESUMO}

O Soil-borne wheat mosaic virus (SBWMV) é transmitido pelo fungo de solo Polymyxa graminis. Em ensaios conduzidos a campo, por dois anos, avaliaram-se a incidência, severidade e presença do vetor do vírus no sistema radicular das gramíneas: aveia (Avena sativa e A. strigosa), azevém (Lilium multiforum), cevada (Hordeum vulgare), milhã (Digitaria sp.), milheto (Pannisetum americanum), milho (Zea mays), papuã (Brachiaria sp.), sorgo (Sorghum bicolor), trigo (Triticum aestivum) e triticale (Triticum secale). A incidência da virose foi calculada com base no percentual de plantas sintomáticas, sendo atribuído notas de 0-5 para determinar o ID (\%) . Os segmentos radiculares foram coletados, corados com solução de lactofenol-azul de algodão e visualizados em microscópio luminoso, atribuindo-se níveis de infestação pela quantidade de grupos de esporos de resistência de P. graminis. Em espécies de aveia, não foram observados sintomas e esporos de resistência do vetor. $\mathrm{Na}$ cultura da cevada, não foram observados sintomas, mas sim esporos de resistência no sistema radicular. Para o triticale e o trigo, na primeira época de plantio, a incidência e ID (\%) foram mais elevados quando comparados à segunda época. Observou-se uma relação direta entre o ID (\%) e a quantidade de esporos de resistência. Nas gramíneas de verão, não foram observados sintomas de SBWMV nem esporos de resistência no sistema radicular.

Palavras-chave adicionais: SBWMV, Furovirus, esporos de resistência, virose.

\section{ABSTRACT \\ Incidence and disease index of Soil-borne wheat mosaic virus on winter cereals and summer grasses associated with the fungus Polymyxa graminis}

The Soil-borne wheat mosaic virus (SBWMV) is transmitted by the fungus Polymyxa graminis. To evaluate the incidence and the disease index (DI\%) and the presence of the vector in the root system, an experiment was carried out using: oat (Avena strigosa and A. sativa), barley (Hordeum vulgare), triticale (Triticum secale), wheat (Triticum aestivum), Lilium multiforum, mayze (Zea mays), sorghum (Sorghum bicolor), Pannisetum americanum, Digitaria sp. and Brachiaria sp. The experiment was conducted during two sowing periods. Incidence was calculated based on the percentage of the symptomatic plants and grades (0-5) were given to determine the DI (\%). Root segments were collected, then stained with solution of cotton blue-lactofenol and visualized in optical microscope. The quantity of resting spores groups was rated. No symptoms were observed on oat species, however, the presence of resting spores in moderate quantities was observed on barley. The incidence and DI (\%) for the triticale and wheat in the first sowing period were higher than in the second one. A direct relationship between DI (\%) and the quantity of resting spores on root was observed. No symptoms of SBWMV or resting spores in the root system of summer grasses were observed.

\section{INTRODUÇÃO}

O trigo (Triticum aestivum L.) é um dos cultivos mais afetados por doenças causadas por fungos, bactérias e vírus (Mehta, 1978). Entre as doenças de importância para a cultura, está a virose causada pelo vírus do mosaico do trigo (Soilborne wheat mosaic vírus, SBWMV) gênero Furovirus (Campbell, 1996), que tem como vetor o fungo Polymyxa graminis Ledingham (Campbell, 1996).

O SBWMV apresenta genoma de RNA bipartido

\footnotetext{
${ }^{\text {*1 }}$ Parte da Dissertação de Mestrado do primeiro autor. Universidade de Passo Fundo; bolsista da Capes
}

encapsulado em partículas alongadas retilíneas, de fita simples e senso positivo (Shirako, 1998). A transmissão do vírus ocorre pela colonização dos pêlos radiculares de plantas através dos zoosporos virulíferos de $P$. graminis, considerado um parasita obrigatório de raízes de gramíneas (Barr, 1979) que pode persistir por longos períodos em raízes em decomposição ou no solo (Adams, 1991).

Os sintomas da virose variam de mosaico verde a mosaico amarelo, ocorrendo mais freqüentemente em plantas com desenvolvimento em áreas mais baixas, especialmente durante extensos períodos de frio e alta umidade do solo (Larsen et al., 1985).

Os fatores que influenciam a transmissão do vírus são 
Incidência e índice de doença do mosaico do trigo em...

os mesmos que afetam o desenvolvimento do vetor. Os zoosporos do fungo requerem umidade para sua mobilidade; assim, as infecções são mais evidentes após extensivos períodos úmidos (Chen et al., 1995), o que favorece a infecção do SBWMV (Himmel et al., 1992). A temperatura ótima para o desenvolvimento do vetor é de $18^{\circ} \mathrm{C}$. A infecção pelo vírus é bem-sucedida quando a temperatura está em torno de 15$18{ }^{\circ} \mathrm{C}$, e os sintomas nas plantas são mais visíveis quando a temperatura é inferior a $20^{\circ} \mathrm{C}$ (Brunt \& Richards, 1989; Chen \& Wilson, 1995). Em lavouras de plantas infetadas, geralmente o $\mathrm{pH}$ do solo é neutro para ligeiramente alcalino (Chen \& Wilson, 1995), porém, segundo Caetano (1982), tem sido freqüente, no sul do Brasil, a ocorrência do mosaico em lavouras de trigo estabelecidas em solos com $\mathrm{pH}$ inferior a 6,0 .

A severidade de infecção nas espécies varia muito, dependendo principalmente da combinação da estirpe do vírus, da cultivar, da idade das plantas quando infetadas e das condições ambientais (Brakke, 1971; Larsen et al., 1985).

A incidência dos sintomas do SBWMV é sempre menor em variedades resistentes, embora a incidência possa atingir 6 a $7 \%$ no campo e $50 \%$ na câmara de crescimento. Por outro lado, a incidência em variedades suscetíveis atinge $100 \%$ em ambas as condições (Campbell et al., 1975).

Em estudos desenvolvidos por Brakke et al. (1965), foi observado o movimento do vírus em raízes e plântulas de cultivares resistentes e suscetíveis. Entretanto, o vírus aparece acumulado em maiores extensões nas raízes de cultivares suscetíveis. As cultivares de trigo resistentes e suscetíveis ao SBWMV fornecem um reservatório do vírus para o vetor, contribuindo para o potencial da doença na estação seguinte.

Myers et al. (1993) encontraram o vírus em raízes de todas as plantas nas cultivares de trigo, que permaneceram a $15{ }^{\circ} \mathrm{C}$, independentemente do nível de resistência da planta ao vírus, mas somente nas cultivares suscetíveis o vírus foi encontrado no tecido foliar. Entretanto, o SBWMV foi detectado nas raízes e nas folhas de todas as cultivares quando as plantas foram colocadas a $23{ }^{\circ} \mathrm{C}$. Conforme os autores, essa mudança na temperatura parece ter suprimido a expressão de resistência ao vírus e seu conseqüente estabelecimento nas folhas. Segundo Campbell et al. (1975), cistosoros de $P$. graminis foram obervados tanto em cultivares resistentes como nas suscetíveis.

Larsen et al. (1985) demonstraram resistência somente contra o fungo vetor, embora Lappierre et al. (1985) tenham encontrado diferentes níveis de resistência para $P$. graminis em cultivares de trigo que exibiam resistência ao SBWMV. Tsuchizaki (1988) observou que as cultivares resistentes não se tornaram infetadas com o SBWMV quando cultivadas em solo infestado, mas $P$. graminis infetou as raízes de cultivares resistentes e suscetíveis. A resistência ao vírus pode se expressar através da redução na replicação do vírus, na quantidade de partículas e no movimento do vírus na planta (Larsen et al., 1985; Hunger et al., 1989; Armitage et al., 1990; Sherwood et al., 1990).

Considerando que não foram encontrados relatos de estudos desenvolvidos no Brasil com relação a incidência do mosaico do trigo em diferentes espécies de gramíneas, o presente trabalho objetivou: avaliar a incidência e o índice de doença do mosaico do trigo em trigo, triticale (Triticum secale Wittmack.), aveia (Avena sativa L. e A. strigosa Schreb.) e cevada (Hordeum vulgare L.); confirmar a presença do vetor $P$. graminis no sistema radicular das plantas de cereais de inverno e correlacionar a intensidade de infecção de raízes pelo fungo com o índice de doença; verificar a presença do vetor $P$. graminis no sistema radicular de gramíneas de verão e correlacioná-la com a incidência do SBWMV.

\section{MATERIAL E MÉTODOS}

O experimento foi conduzido na área experimental da Embrapa Trigo em Passo Fundo, RS. Foram utilizadas cinco espécies de cereais de inverno com diferentes reações de resistência ao SBWMV (Tabela 1). O experimento foi conduzido em duas épocas de semeadura (20 de junho e 15 de julho respectivamente) em solo naturalmente infestado com P. graminis. O preparo, a adubação do solo e os tratamentos fitossanitários seguiram as recomendações para a cultura (Recomendações da Comissão Sul-Brasileira de Pesquisa de Trigo, 1998).

O delineamento experimental utilizado foi inteiramente casualizado (em função da distribuição do vetor no solo) com duas repetições. Cada repetição constou de uma parcela com cinco linhas de $2 \mathrm{~m}$ de comprimento, espaçamento de $0,25 \mathrm{~m}$ entre linhas e densidade de 300 sementes aptas por metro quadrado.

No estágio de emborrachamento [Escala de FeeksLarge segundo Mehta (1978)], coletaram-se as plantas em uma linha de $2 \mathrm{~m}$ lineares de cada parcela para determinar a incidência com base no percentual de plantas com sintomas, sendo atribuídas notas para cada planta, conforme escala de Barbosa (1996): 0 - ausência de sintomas; 1 - folhas do colmo principal e alguns perfilhos apresentando mosaico leve, sem estrias, ausência de nanismo ou de enrosetamento; 2 - folhas do colmo principal e alguns perfilhos com mosaico leve, com estrias pouco pronunciadas, lesões coalescentes, sem nanismo e sem enrosetamento; 3 - folhas do colmo principal e dos vários perfilhos com mosaico e/ou estrias características generalizados, lesões coalescentes, nanismo e/ou enrosetamento ausentes; 4 - folhas do colmo principal e dos vários perfilhos apresentando mosaico e/ou estrias características generalizados, lesões coalescentes, nanismo e/ou enrosetamento pronunciados; e 5 - folhas com mosaico comum ou estriado bastante pronunciados e lesões totalmente coalescentes, severo nanismo e/ou enrosetamento, podendo ser acompanhado de ausência de espigamento e/ou morte da planta. A partir das notas, foram determinados os índices de doença (ID) através da fórmula de Mckinney's (Tanaka, 1990), onde ID $(\%)=100 . \Sigma[(f . v) /(n . x)]$, sendo $I D$ - índice de doença; $f$ - número de plantas com a mesma nota; $v$ - nota observada; $n$ - número total de plantas avaliadas e $x$ - nota máxima da escala. 
Para avaliar a presença do fungo no sistema radicular, as raízes foram coletadas das mesmas plantas amostradas para avaliar o ID. A amostra foi constituída de dez segmentos radiculares de $2 \mathrm{~cm}$ de comprimento, coletados aleatoriamente de cada grupo de notas conforme a escala de notas. Na mesma área do experimento, foram coletadas ao acaso 20 plantas de azevém (Lolium multiflorum Lam.).

Em sucessão ao experimento com cereais de inverno, foi implantado um experimento com gramíneas de verão, sendo utilizado milho (Zea mays L.) cv. Agroceres 1051, sorgo (Sorghum bicolor L.) Macho Estéril, e milheto (Pennisetum sp.) cv. Comum - RS. O delineamento experimental utilizado foi inteiramente casualizado com três repetições. Cada repetição constou de uma parcela de quatro linhas com $4 \mathrm{~m} \mathrm{de}$ comprimento, com espaçamento de 0,50 m entre linhas. Dois meses após o plantio, em cada parcela, foram coletadas dez plantas, das quais foram retirados cinco segmentos radiculares de $2 \mathrm{~cm}$ de cada planta. A amostra foi constituída de 50 segmentos por cultura. Nessa mesma área, foram coletadas aleatoriamente 20 plantas de milhã (Digitaria sp.) e papuã (Brachiaria sp.).

O protocolo estabelecido para observação do fungo no sistema radicular constou da coleta de segmentos radiculares $(2 \mathrm{~cm})$; lavagem em água corrente; armazenagem a $-20{ }^{\circ} \mathrm{C}$, para posterior análise; imersão dos segmentos radiculares em solução de lactofenol-azul de algodão 7\%; fervura por um minuto (na mesma solução de lactofenol-azul de algodão); lavagem em água; deposição dos segmentos entre lâminas de microscópio seguidos de pressão; montagem da lâmina em lactofenol; e observação ao microscópio luminoso. Foram atribuídos níveis de infestação de acordo com a quantidade de grupos de esporos de resistência por segmento radicular: (0) ausência de grupos de esporos de resistência; (1) de um a cinco grupos de esporos de resistência; (2) de seis a 20 grupos de esporos de resistência; (3) acima de 20 grupos de esporos de resistência.

\section{RESULTADOS E DISCUSSÃO}

Para as espécies de aveia e de cevada, tanto na primeira quanto na segunda época de plantio, a incidência e conseqüentemente o ID foram 0\%. Brakke (1971) mencionou ser a cevada suscetível ao SBWMV. No presente estudo, não foram observados sintomas de mosaico ou outro sintoma atribuídos ao vírus em plantas de cevada e de aveia, embora, esporos de resistência tenham sido encontrados no sistema radicular de plantas de cevada. Entretanto, não ficou claro se a inexistência de sintomas estava relacionada à pressão de inóculo ou a uma característica varietal.

Para triticale e trigo, a incidência mais elevada do SBWMV foi observada na primeira época de plantio. O mesmo resultado foi observado para o ID (Tabela 1). Esses resultados indicam que a severidade da infecção varia muito dependendo da cultivar, da idade da planta na época da infecção e das condições ambientais (Brakke, 1971; Larsen et al., 1985).

Os resultados encontrados são semelhantes aos observados por Campbell et al. (1975) que relataram uma incidência de 6 a 7\% em cultivares resistentes e até de $100 \%$ em cultivares suscetíveis.

Com relação ao nível de infestação de esporos de resistência no sistema radicular, observou-se que, embora as

TABELA 1 - Índice de doença (ID) e incidência do Soil-borne wheat mosaic virus (SBWMV) comparando com o nível de infestação nas raízes pelo fungo Polymyxa graminis em cereais de inverno, em duas épocas de plantio

\begin{tabular}{|c|c|c|c|c|c|c|}
\hline \multirow{2}{*}{$\begin{array}{c}\text { Espécie/Cultivar/ } \\
\text { Reação de resistência* }\end{array}$} & \multicolumn{3}{|c|}{ Época 1} & \multicolumn{3}{|c|}{ Época 2} \\
\hline & $\begin{array}{l}\text { ID } \\
(\%)\end{array}$ & $\begin{array}{c}\text { Incidência } \\
(\%)\end{array}$ & $\begin{array}{c}\text { Nível de infestação } \\
\text { nas raízes }\end{array}$ & $\begin{array}{l}\text { ID } \\
(\%)\end{array}$ & $\begin{array}{c}\text { Incidência } \\
(\%)\end{array}$ & $\begin{array}{c}\text { Nível de infestação } \\
\text { nas raízes }\end{array}$ \\
\hline Avena strigosa (I) & 0 & 0 & 0 & 0 & 0 & 0 \\
\hline \multicolumn{7}{|l|}{ Avena sativa } \\
\hline UPF 16 (I) & 0 & 0 & 0 & 0 & 0 & 0 \\
\hline \multicolumn{7}{|l|}{ Hordeum vulgare } \\
\hline BR 2 (I) & 0 & 0 & 1 & 0 & 0 & 1 \\
\hline \multicolumn{7}{|l|}{ Triticum secale } \\
\hline Iapar $23(\mathrm{~S})$ & 87,3 & 100 & 3 & 72,7 & 100 & 3 \\
\hline Embrapa 53 (MR) & 15,8 & 62 & 2 & 12,3 & 25,5 & 1 \\
\hline \multicolumn{7}{|l|}{ Triticum aestivum } \\
\hline BR 23 (S) & 37,3 & 100 & 3 & 19,1 & 53 & 3 \\
\hline OR $1(\mathrm{~S})$ & 36,1 & 64,5 & 3 & 36,2 & 73,5 & 2 \\
\hline IAC 5-Maringá (S) & 23,4 & 54,5 & 1 & 47,6 & 59 & 3 \\
\hline Embrapa 27 (S) & 24,1 & 47 & 1 & 24,3 & 53,5 & 3 \\
\hline BR 32 (MR) & 34,4 & 100 & 2 & 9,6 & 48 & 3 \\
\hline Embrapa 120 (MR) & 37,3 & 100 & 3 & 13,2 & 31 & 1 \\
\hline Embrapa $16(\mathrm{R})$ & 9,5 & 33 & 1 & 5,9 & 27,5 & 1 \\
\hline
\end{tabular}

* Reação de resistência das espécies conforme Recomendações da Comissão Sul-Brasileira de Pesquisa de Trigo (1998), I- Indeterminado; S - Suscetível; MR - Moderadamente Resistente; $\mathrm{R}$ - Resistente

*** (0) Ausência de grupos de esporos de resistência; (1) De 1 a 5 grupos de esporos de resistência; (2) De 6 a 20 grupos de esporos de resistência; (3) Acima de 20 grupos de esporos de resistência 
Incidência e índice de doença do mosaico do trigo em...

plantas de cevada não tivessem manifestado sintomas da virose, o fungo estava presente no sistema radicular em quantidade de um a cinco grupos de esporos de resistência. Esse fato sugere que a cevada pode ser resistente ao vírus, mas não ao fungo, conforme já afirmaram Lommel \& Willis (1984) com relação às cultivares de trigo resistentes ao SBWMV.

Nas cultivares de trigo e triticale estudadas, excetuando-se 'IAC 5-Maringá', observou-se uma relação direta entre o ID do vírus na parte áerea com o nível de infestação das raízes por $P$. graminis nas duas épocas de plantio (Tabela 1). Os níveis mais altos de esporos de resistência foram encontrados nas cultivares suscetíveis e moderadamente resistentes, ao passo que um pequeno número de grupos de esporos de resistência foi observado na cultivar de trigo resistente. Esse resultado foi semelhante ao relatado por Himmel et al. (1991) que observaram menor número de esporos de resistência nas cultivares resistentes do que nas cultivares suscetíveis. Nas cultivares IAC 5-Maringá e Embrapa 27 (suscetíveis ao SBWMV), o número de grupos de esporos de resistência foi reduzido na primeira época quando comparado à segunda época, embora o ID e a incidência tenham sido semelhantes nas duas épocas. Sugerindo, neste caso, que um pequeno número de grupos de esporos de resistência são suficientes para induzir os sintomas da virose. Plantas invasoras de azevém coletadas na mesma área não mostraram sintomas de SBWMV e, tampouco, o sistema radicular continha esporos de resistência de $P$. graminis.

Nas raízes de gramíneas de verão não foram encontrados quaisquer indícios de esporos de resistência do fungo, contrariando o proposto por Eversmeyer et al. (1983), que sugere que o sorgo poderia se constituir em um reservatório do vírus e do vetor. Com relação ao milho, as observações do presente estudo estão de acordo com as citações de Brakke (1971), segundo os quais o milho não é suscetível ao SBWMV nem a $P$. graminis. Dessa forma, torna-se difícil afirmar que as gramíneas de verão estudadas sejam resistentes ao SBWMV. Possivelmente, as plantas apresentam resistência ao vetor e, como conseqüência, ao vírus, indicando a necessidade de estudos mais detalhados para melhor elucidar a relação vírus/vetor nessas espécies vegetais.

\section{REFERÊNCIAS BIBLIOGRÁFICAS}

ADAMS, J.M. Transmission of plant viruses by fungi. Annals of Applied Biology 118: 479-492. 1991.

ARMITAGE, C.R., HUNGER, R.M., SHERWOOD, J.L. \& WEEKS D.L. Relationship between development of hard red winter wheat and expression of resistance to wheat soilborne mosaic virus. Plant Disease 74:356-359. 1990.

BARR, D.J.S. Morphology and host range of Polymyxa graminis, Polymyxa betae, and Ligniera pilorum from Ontario and some other areas. Canadian Journal of Plant Pathology 1:85-94. 1979.

BARBOSA, M. M. Controle genético da resistência ao vírus do mosaico do trigo em Triticum aestivum L. Thell (Dissertação de Mestrado). Uberlândia. Universidade Federal de Uberlândia. 1996.

BRAKKE, M.K., ESTES, A.P. \& SCHUSTER, M.L. Transmission of soil-borne wheat mosaic virus. Phytopathology 55:79-86. 1965.

BRAKKE, M.K. Soil-borne wheat mosaic virus. In: Descriptions of Plant Viruses. 77. 1971.

BRUNT, A.A. \& RICHARDS, K.E. Biology and molecular biology of furoviruses. Advances in virus research 36:1-32. 1989.

CAETANO, V.R. Mosaico do trigo transmitido pelo solo "wheat soilborne mosaic virus" Tobamovirus. In: Fundação Cargill. Trigo no Brasil. Campinas, 1982. v.2, pp.563-570.

CAMPBELL, L.G., HEYNE, E.G., GRONAU, D.M. \& NIBLET, C. Effect of soilborne wheat mosaic virus on wheat yield. Plant Disease Reporter 59:472-476. 1975.

CAMPBELL, R.N. Fungal transmission of plant viruses. Annual Review Phytopathology 34:87-108. 1996.

CHEN, J. \& WILSON, T.M.A. Taxonomy of rigid rod-shaped viruses transmitted by fungi. Agronomie 15:421-426. 1995.

CHEN, J., STUART, A., MACFARLANE, S.A \& WILSON, T.M.A. Effect of cultivation temperature on the spontaneous development of deletions in soilborne wheat mosaic furovirus RNA 2. Phytopathology 85:299-306. 1995.

EVERSMEYER, M.G., WILLIS, W.G. \& KRAMER, C.L. Effect of soil fumigation on occurrence and damage caused by soilborne wheat mosaic. Plant Disease 67:1000-1002. 1983.

HIMMEL, P.T., HEWINGS, A.D. \& GLAWE, D.A. Incidence of soilborne wheat mosaic virus and its reported vector, Polymyxa graminis, in field-grown soft red winter wheat. Plant Disease 75:1008-1012. 1991.

HIMMEL, P.T., SIMMONS, F.W., HEWINGS, A.D. \& GLAWE, D.A. Effects of soil water status on infection of soft red winter wheat by soilborne wheat mosaic virus. Canadian Journal of Plant Pathology 14:147-151. 1992.

HUNGER, R.M., ARMITAGE, C.R. \& SHERWOOD, J.L. Effects of wheat soilborne mosaic virus on hard red winter wheat. Plant Disease 73:949-952. 1989.

LAPIERRE, H., COURTILLOT, M. KUSIAK, C. \& HARIRI, D. Field resistant of autumn-sown wheat to wheat soil-borne mosaic virus. Agronomie; Science des Productions Vegetals at the Environment 5:65-572. 1985.

LARSEN, H.J., BRAKKE, M.K. \& LANGENBERG, W.G. Relationship between wheat streak mosaic virus and soilborne wheat mosaic virus, disease resistence, and early growth of winter wheat. Plant Disease 69:857-862. 1985.

LOMMEL, S.A. \& WILLIS, W.G. The role of wheat spindle streak and wheat soilborne mosaic virus in an epiphytotic of resistance wheat in Kansas. Phytopathology 74:844. 1984. (Abstract)

MEHTA, Y. R. Doenças do trigo e seu controle. São Paulo: Agronômica Ceres, 1978.

MYERS, D.L., SHERWOOD, J.L., SIEGERIST, W.C. \& HUNGER, R.M. Temperature-influenced virus movement in expression of resistance to soilborne wheat mosaic virus in hard red winter wheat (Triticum aestivum). Phytopathology 83:548-551. 1993.

RECOMENDAÇÕES DA COMISSÃO SUL-BRASILEIRA DE PESQUISA DE TRIGO. XXX Reunião da Comissão SulBrasileira de Pesquisa de Trigo. Chapecó. 1998. p.82.

SHERWOOD, J.L., MEYERS, L.D., \& HUNGER, R.M. Expression of resistance of hard red winter wheat to wheat soilborne mosaic virus. Phytopathology 80:1033. 1990. (Abstract).

SHIRAKO, Y. Non-AUG translation initiation in a plant RNA virus: 
a forty-amino-acid extension is added to the $\mathrm{N}$ terminus of the soil-borne wheat mosaic virus capsid protein. Journal of Virology 72:1677-1682. 1998.

TANAKA, M.A.S. Patogenicidade e transmissão por semente do agente causal da ramulose do algodoeiro. (Tese de Doutorado).
Piracicaba: ESALQ, 1990.

TSUCHIZAKI, T. Resistance of roots of barley and wheat plants to the infection of soil-borne wheat mosaic virus. Page 56 in: Proceedings of the 5 th International Congress of Plant Pathology. Kyoto, Japan. 1988. p.56. 